\title{
UM MILITANTE PERNAMBUCANO NA EUROPA ULTRAMONTANA: ODILON ALVES PEDROSA E O MISSIONARISMO INTELECTUAL CATÓLICO (1926-1927) ${ }^{1}$
}

\author{
Ramsés Nunes e Silva ${ }^{2}$
}

José António Martin Moreno Afonso ${ }^{3}$

\begin{abstract}
"Entre as cousas que li estava a palavra da língua mãe, da qual sou admirador, e na qual falava a voz dos católicos: nossa luta era no velho continente a mesma a se desenrolar em Pernambuco. Não era outro o inimigo herege que agia a tentar alistar nossas crianças e nossas escolas. Lutávamos, nós, os brasileiros e os portugueses, na mesma trincheira" ${ }^{4}$.
\end{abstract}

\section{RESUMO}

A parcela de engajamento político, que configurou a ação da Igreja Católica, na transição entre os séculos XIX e XX, possui suas raízes fincadas no "chamamento à missão". Dispositivo engajamento que "alistava" jovens, internados nas centenas de seminários, espalhados pelo mundo católico. Estes últimos, a se considerarem francamente ameaçados pelo cientificismo, e pelos seus desdobramentos, na esfera da instrução. Este artigo, se dedica a refletir sobre a trajetória de Odilon Alves Pedrosa, padre e intelectual, engajado nas querelas discursivas dos anos 1920. Particularmente, na análise de seu engajamento, nas querelas pela "reconquista de espaço da instrução católica", em Pernambuco e Paraíba. Trajetória marcante, posto que encerra os signos de uma militância urdida, como muitos antes dele, no Pontifício Colégio Pio Latino Americano, em Roma, e levada consigo ao Brasil. Para tanto, nos utilizamos do mapeamento de suas leituras, viagens e produção literária, vivenciadas nos dois lados do Atlântico.

Palavras-chave: Militância; Educação Católica; Missionarismo

\section{A MILITANT PERNAMBUCANO IN ULTRAMONTANE EUROPA: ODILON ALVES PEDROSA AND INTELLECTUAL CATHOLIC MISSIONARISMO PORTUGUESE LANGUAGE (1926-1927).}

\begin{abstract}
The share of political engagement, which sets the action of the Catholic Church, in the transition between the nineteenth and twentieth centuries, has its roots planted in the "call to mission". Pickup device that "list" young, interned in hundreds of seminars spread by the Catholic world. These latter are considered downright threatened by scientism, and its consequences, in education sphere. This article is dedicated to reflect on the trajectory of Odilon Alves Pedrosa, priest and intellectual, engaged in discursive disputes of the 20s of the twentieth century. In particular, the analysis of their commitment to "reconquest space of Catholic education", in Pernambuco e Paraíba. Remarkable trajectory, since it contains the signs of a woven militancy, as in many other seminarians before him, at the Pontifical College Pio Latino Americano in Rome, and he took with him to Brazil. For this, we use the mapping of his reading, travel and literary production, lived on both sides of the Atlantic.
\end{abstract}

Keywords: Militancy; Catholic Education; Missionary 
Os momentos de transição histórica se projetam como interstícios de tempo entre mundos que se estranham e convergem. Dimensionados pelas continuidades e pelas dicotomias, pelos "impactos de mudança" e "acomodações", de qualquer forma, nem sempre parecem findos os rumos da mudança e da permanência, seja para qual conjuntura acabem propostas.

Haja vista que se apresentem como signos impactantes, pois "amarram significados" e interpretações para dado tempo, entre discursos e interpretações atreladas às transformações e protagonismos, também se destacam indivíduos que vivenciam o transcurso das mediações, envolvidos que estão, por exemplo, com seus dispositivos de afirmação discursiva. Seus habitus, como nos aponta Pierre Bourdieu (1987, p. 78).

Uma parte considerável deles, cingidos pela afirmação da conquista, por simbioses e negações, mudanças e permanências que são próprias à natureza das passagens, de uma época à outra. Entretanto, há os que preferem o combate imediato a quaisquer rupturas culturais e sociais.

$\mathrm{Na}$ transição entre o Oitocentos e o século XX, era visível certo ambiente de conflito, dentro do que se apresentava como uma construção discursiva de embates, tornada ampla, pois era maturada e tecida por uma gama, cada vez maior, de intelectuais. Particularmente, a defender certos princípios instrucionais, à sombra dos preceitos liberais e laicos, arraigados pelas conquistas do evolucionismo e do cientificismo ou ortodoxamente católicos, já que sedimentados pela reação ultramontana. Como, por exemplo, Ramalho Ortigão em Portugal, ou do lado católico, Tristão de Athayde no Brasil, respectivamente.

Tanto no Velho Mundo, quanto na América do Sul, a dinâmica intensa dos "confrontos de papel", ordenados pelas publicações jornalísticas e literárias, fazia-se apresentar como um front a ser ampliado, na medida em que o impacto dos discursos pela transformação e ingerência clerical parecia ser atacado nos dois lados do Atlântico.

Daí, seja perceptível uma espécie de "vertigem" sociocultural, destacada por Pintassilgo (2013, p. 12), causada pela transição entre os séculos. Uma manifestação pontual naqueles tempos que aceleravam as relações sociais e culturais. No Brasil, "vertigem" de profundo impacto, segundo Neves (2003, p. 19-56) nas sociabilidades que se verificaram urgentes. Manifestação de embates, a serem protagonizados por novos atores sociais, imbricados entre profissionais liberais e uma classe média sequiosa por espaço. Naquele interstício, toda uma nova geração de clérigos se entrincheiraria, a partir dos seminários, arquidioceses e colégios diocesanos.

Afinal, aquele universo de circulação de ideias a comporem protagonismos influenciados pelo cientificismo, e também pela resistência cristocêntrica, numa outra ponta do novelo das tramas históricas, já eram manifestações factíveis, em que pesem suas representações distintas e contraditórias, posto que essas mesmas ideias fossem assentadas nas mudanças, mas também na defesa de continuidades, a elaborarem outras percepções da escola, métodos e práticas instrucionais.

Outrossim, eram delimitados sentidos específicos para fenômenos como a secularização, nos moldes do que nos apontam Marramao (1999, p. 23), Mezzoti (1998, p. 49-60) e Silva (2006, p. 23). Meandros e querelas ajustáveis a universos de representação em comum ou diametralmente contrários, em parte, a se apresentarem defensáveis no que Chartier (1990, p. 178-179) chama de comunicação do escrito. 
É importante lembrar: foi exatamente naquele transcurso, entre o Oitocentos e o século XX, que se reafirmou como profissão de fé a defesa de "visões de instrução", assentadas, diga-se, para cristalizar projetos de ensino, num mundo que se queria, ou se postulava moderno. Pior, segundo o discurso religioso, cada vez mais dessacralizado, naquilo que Ozouf (1976, p. 30) define como uma cada vez maior transferência da sacralidade, do campo religioso para o secular. Instituições como a Igreja Católica, naquela conjuntura, já estavam a produzir extensa lista de Encíclicas e, no Brasil proclamada a República, Cartas Pastorais. Estes últimos documentos, de forte teor político, moral e doutrinário, escritos para afirmarem o "bom combate", pela manutenção da influência cultural da Igreja junto às demandas modernas, como destaca Miceli (1988, p. 23).

Documentos, aliás, a tentarem instrumentalizar os quadros clericais, a partir de uma extensa literatura crítica. Textos que, afinal, no que tange às lideranças romanas, funcionariam como guias sociais, de marcante escopo militante. Ao mesmo tempo, dentro da esfera da Igreja Católica, seus quadros de jovens intelectuais, formados nos bancos centenários de seminários, como os de Olinda, acabavam imbricados como agentes, notadamente, junto às escolas e docentes daquela sociedade em transformação.

Principalmente, na esfera das querelas doutrinárias, a proporem uma tomada de espaço que se tornava urgente, segundo argumentavam sucessivos pontífices: a escola católica como lugar de "ajustamento moral", e as demais confissões religiosas na condição de potenciais rivais. Erros e "signal dos tempos", como nos aponta Henriques (Carta Pastoral, 1897, p. 2), todos a serem corrigidos pela instrução religiosa. Da mesma forma, a Carta Pastoral Coletiva de 1915, assinada por Dom Leme, entre outras lideranças, espécie de documento fundante daquela que se apresentava como uma espécie de "nova militância". Militância, diga-se, centrada na circulação de ideias centradas no teor de textos, como os das encíclicas Quanta Cura, escrita pelo Papa Pio IX, e Rerum Novarum, ratificada pelo Papa Leão XIII, todas a serem estudadas como textos-base nos seminários.

Da mesma forma, apresentava-se viável e desejável a formação de um lastro intelectual com posturas políticas factíveis, naquela espécie de "alistamento" da juventude brasileira, apta a se dedicar a uma vida religiosa ativa, entre os círculos da militância. Notadamente, na esfera das práticas, representações e sociabilidades produzidas pelo universo instrucional, naquilo que argumenta Julia (2001, p. 11) serem especificidades $d a$ cultura escolar.

Muito do que se postulava em termos de cotidianidade para a escola, via currículos, modelos e instrumentalidades para a educação, circulava nas mais diversas esferas intelectuais. Eram muitos os agentes a defender a instrução laica, ou confessional, que acabavam por se tornar os principais articuladores de uma complexa rede de circulação de leituras.

Lugares e suportes jornalísticos, por exemplo, de onde partiam e onde eram cristalizadas ideias a serem constantemente ajustadas aos interesses de indivíduos, instituições e condições culturais. Na mesma balança de importância, na densidade de postulados, estavam o cientificismo e a romanização, como bens simbólicos em cheque, dentro da sociedade bifurcada, entre Deuses e Césares, nas palavras de Catroga (2010, p. 22).

Afinal, nunca foi tão imprescindível aos católicos, por todo o Ocidente, naquele momento de afirmação das representações culturais, afirmarem-se no combate às práticas instrucionais, segundo Villaça (2006, p. 45), identificadas como errôneas. 
Destarte, a sociedade secular, que se apresentava em curso sob diversas formas na Europa, como nos aponta Catroga (2010, p. 23) e no Brasil, segundo Silva (2006, p. 60), Azzi (2008, p. 11- 50) e Miceli (1988, p. 56). Simbologias e práticas, nas quais se assentavam protagonismos ciosos por acharem espaço no universo instrucional. Universo aquele, na reflexão de Cambi (2002, p. 340-370), em ebulição, ao chegar o século XIX a seu término. Aspecto a levarmos em consideração, dentro do que Catroga (2010, p. 34) destaca como relação específica da dinâmica social entre o Estado e a sociedade civil, no tocante à secularização. Naquele momento, fenômeno a se fazer ainda mais contundente, inclusive a partir de demandas instrucionais não alinhadas com o catolicismo ou dele francas concorrentes.

Entre elas, as que se lançavam à alternativa instrucional protestante. Em Portugal, como acentua Afonso (2001, p. 34), inicialmente em espaços cosmopolitas e, no Brasil, de forma cada vez mais acentuada a partir de 1891. Momento das manifestações de debates acirrados, atrelados às querelas pela liberdade de culto, instalada pela República.

Da mesma forma, também da manifestação daquilo que Azzi (2008, p. 11) chama de estratégia de sacralização do Brasil. Esta última, a incluir o combate às práticas instrucionais protestantes, tanto na representacão de seus discursos quanto na fundação de escolas. Estas últimas, no Brasil da transição entre Monarquia e República, alvo de discussões sobre a maior ou menor influência da cultura clerical.

Naquela transição, a dimensão cultural e social, que acabou por produzir toda uma geração de intelectuais brasileiros, muitos deles engajados na defesa da catolicidade dentro dos preceitos romanizados, pode ser entendida como de amplo impacto nos meios letrados. Não se restringiu aos primeiros anos da República brasileira, mas às décadas anteriores, ainda no Império.

\section{Soldado católico alistado: um mundo católico a reconquistar}

Um diferencial da década de 1910 e nos trinta anos subsequentes foi a intensidade dos postulados missionários orquestrados pelos pontífices, nos quais se sedimentava a necessidade de capacitação de seminaristas e demais lideranças clericais, para estudarem na Europa. É o que nos conta Martina (1996, p. 34) e Zagheni (1999, p. 43).

Outrossim, não foram poucas as articulações entre bispos e lideranças abastadas, para que jovens estudantes: 1) ingressassem na vida religiosa, como carreira política; e 2) se deslocassem em missão para espaços de formação superior, ou sedes doutrinárias, nos quais estavam os centros da pregação católica. Se possível em Roma, a capital do catolicismo e base de projeção intelectual, tanto das futuras lideranças católicas, a se fixarem como agentes influentes na hierarquia clerical, quando do retorno para suas arquidioceses, quanto jornalistas, articuladores políticos e educadores dispostos a aceitarem a ingerência da Igreja em seus meios.

É o caso de Odilon Alves Pedrosa, jovem filho das elites pernambucanas. Nascido em São Vicente Ferrer, Zona da Mata de Pernambuco, no seio de uma família de proprietários, os Alves Pedrosa, com uma profunda tradição católica. Aspecto que além de estar vinculado à cultura servia aos interesses da parentela. Dentro do que se esperava de um filho das elites pernambucanas, foi encaminhado, desde muito cedo, ao Seminário de Olinda, instituição onde iniciaria seus estudos eclesiásticos. 
Destacou-se pelo envolvimento nos círculos literários do seminário e demais atividades discentes, tanto na Europa quanto no Brasil, onde foi editor da Gazeta de Nazaré e do jornal A Imprensa, periódicos católicos de suma importância na militância católica dos anos 1920 e 1930. No tocante à sua trajetória intelectual esteve, como muitos oriundos dos engenhos da Zona da Mata, a vivenciar os embates discursivos no Brasil, ainda durante sua formação inicial no Seminário de Olinda, vivenciada entre 1921 e 1925 exato momento de uma série de reformas instrucionais - e na visita pastoral que realizou à Itália e a Portugal, no ano de 1927. Evento que nos desperta o interesse por ter como consequência direta o aprofundamento de seu engajamento militante, e a aquisição de uma série de livros apologéticos, filosóficos e pedagógicos, muitos em língua portuguesa. Parte considerável deles, usados nos anos seguintes, e que acabariam em sua biblioteca particular. De qualquer forma, ainda em Olinda, no início da década de 1920, internado como seminarista, era leitor assíduo de Jackson de Figueiredo, Senna Freitas e Alceu Amoroso Lima.

É o que atesta a assinatura da revista $A$ Ordem, a principal publicação católica do centro Dom Vital, e uma série de livros apologéticos mantidos em sua biblioteca particular. Daí, também, a formação de um núcleo de leituras que o acompanhariam na função de jornalista e educador. Tanto as que se realizaram na Europa quanto as que acabaram por formar uma parte de seus preceitos formativos, enquanto seminarista e futuro intelectual engajado. Especialmente, junto à militância que podemos verificar ter existido naquele universo, a projetar ações, nas quais estavam dísticos pontuais para estudantes missionários: o alinhamento com os postulados da romanização enquanto fenômeno religioso/político e, de forma contundente, a afirmação do modelo instrucional católico, francamente contrário ao protestante.

Aspecto marcante, diga-se, na formação do jovem seminarista (1918-1927), e em seus anos de militância enquanto padre (1927-1982), período no qual exerceu liderança, destacando-se no interior de Pernambuco e Paraíba. Uma prática na qual se lançou o jovem Odilon Pedrosa, em comum acordo com as mentalidades formadas dentro da esfera de leituras que foi sedimentada nos meses passados em Roma, imerso na biblioteca da Pontifícia Universitá Gregoriana, na delegação brasileira do Colégio Pio Latino-Americano e nos dias de visita a Braga e Porto (Portugal), na primavera de 1927.

Visita relembrada por Pedrosa (1927, p. 23), em seu Diário de Estudante em Roma: "Na ribeira do Porto, tanto quanto a meditar às margens do Tibre, ou a ouvir os sinos das Igrejas de Braga. Ali, reafirmei minhas escolhas. Saí do Brasil recruta, retornei combatente armado com as palavras que bebi”.

O alistamento, junto a outros jovens estudantes internados no Seminário de Olinda, para se lançarem a completar os estudos na Europa, iniciado no inverno europeu de 1927, acabaria como uma consequência natural nas pretensões da Cúria para seu "exército eclesiástico". Exército formado nos bancos dos seminários, e também junto às pretensões de realização pessoal de estudantes como Odilon Pedrosa.

Com o reforço do clima de missionarismo, que tomava o universo católico, tanto para a chegada ao Brasil de padres estrangeiros e congregações a partir da patronagem, quanto para a ida de estudantes para junto da Sé romana, segundo Azzi (2008, p. 34- 50), sua trajetória cumpriria um vaticínio duplo: de pupilo da patronagem familiar, a financiar seus estudos, e do vínculo direto com as autoridades episcopais locais. No caso específico de Odilon Pedrosa, do bispo e benfeitor Dom Ricardo Ramos de Castro Villela. 
Destarte, estava em jogo a permanência da ofensiva da Igreja contra toda sorte de religiões, preceitos evolucionistas e doutrinas espiritualistas que chegavam livremente ao Brasil desde a Constituição de 1891, segundo Pedrosa (1950, p. 10), restando àquela instituição "a preparação dos seminaristas contra possíveis adversários, formando-os nas "verdades dogmáticas" e colocando-os "a par das polêmicas, e embates, que se espalhavam in loco". Inteirava-se, assim, o seminarista: a quem deveria dar combate, e a quais pressupostos atacar no trânsito dos estudos que realizava.

Aqueles mesmos, identificados pela cúpula romana, doutrinariamente, moldados como inimigos de fé, passariam a ser estudados detalhadamente nos corredores das instituições educacionais eclesiásticas do Vaticano. Algumas delas, especializadas no acolhimento/instrução de sul-americanos, tais como o Colégio Pio Latino-Americano.

Todas elas, obedecendo a uma lógica de reação contínua a todo e qualquer possível ameaça, oriunda dos estratos sociais e setores intelectuais que se fizessem representar a partir de postulados laicistas, fossem quais fossem as circunstâncias e oportunidades oferecidas. Nas escolas, instituições e nos meios sociais em que a Igreja queria que trabalhassem zelosamente seus seminaristas, estaria o front a ser ocupado por um protagonismo militante.

Para tanto, servia o rigor da educação romana, a transferir jovens para o mergulho numa experiência cosmopolita. Se possível no estrangeiro, e que fosse impactante no reforço a uma visão da centralidade que deveria ocupar Roma na hierarquia eclesiástica. Deve-se observar que tal encaminhamento de seminaristas já era uma realidade desde o Oitocentos, com a presença efetiva de brasileiros junto às instituições clericais romanas.

Era sintomático daí, no âmbito do papado dos anos 1920, que tivessem lugar inúmeras tentativas de interpretação da secularização, e o papel que teria a Igreja na disposição da sociedade que se avizinhava. Pontífices como Leão XII estariam vigilantes quanto às ações a serem tomadas no sentido de postularem soluções para as questões que afetavam as sociabilidades que a Igreja teria que enfrentar, inclusive, junto à formação de seus futuros padres naquelas escolas clericais, de vários níveis, corroborando estratégias interpretativas do papel que teria a Igreja junto à sociedade civil.

Emerge assim o duplo aspecto tático da linha de ação leonina: de um lado a oferta de apoio católico aos partidos liberais da "ordem" (...) e de outro lado a exigência absoluta de reintroduzir nas legislações modernas alguma forma de poder eclesiástico sobre a sociedade. O papa em suma, com grande flexibilidade, reinvindica uma chefia cristã para a ordem civil (MARTINA, 1996, p. $155)$.

Em todos os espaços arquidiocesanos na América do Sul se investia naqueles jovens estudantes a partir de critérios meritocráticos, principalmente, na possibilidade de formação de futuros articuladores políticos, juristas e jornalistas, todos a militarem nas futuras arquidioceses em que estariam a atuar, após suas respectivas ordenações.

Roma, particularmente, vivia um novo momento de combatividade junto à comunidade católica europeia e produzia, febrilmente, uma grande quantidade de documentos, debates e polêmicas publicadas nos órgãos oficiais do estado eclesiástico. Com o devido patrocínio familiar, Odilon Pedrosa chegaria à Itália exatamente num momento de forte retomada de certa efervescência contra o universo sociocultural de outras matrizes religiosas.

Naqueles anos, a efetiva imersão de um grande grupo de seminaristas brasileiros a beber na fonte da centralização e de uma ortodoxia no trato com outras confissões, seria 
contundente, principalmente, pela atenta e arguta participação de estudantes na Pontifícia Universitá Gregoriana.

Aquela instituição, responsável pelo acolhimento de estudantes católicos oriundos da América, diga-se, representou profunda influência no perfil intelectual de Odilon Alves Pedrosa. Afinal, a partir de suas palavras: os inimigos liberais eram agora mundiais $e$ estavam por toda parte, como diriam sucessivamente as cartas pontificiais, publicadas e a circularem pelos corredores daquela instituição, todas lidas com afinco pelo seminarista, como atesta Pedrosa (1927, p. 12). Quer a produzirem sob ele uma percepção negativa sob a forma como se projetava o ensino leigo, nos países republicanos, quer como se postulavam os projetos de separação do Estado, frente à Igreja ou práticas instrucionais não católicas. Daí a acreditarem os estudantes como Odilon Pedrosa em soluções pontuais para o futuro imediato: combater qualquer instrução que não fosse a católica. Como seminarista, Odilon Pedrosa se colocava desde o Brasil como a pertencer a uma espécie de exército doutrinário onde a mundanização das relações era o "inimigo cultural" a ser derrotado. Função que acreditava ter comovente clerical, e que milhares de jovens como ele abraçariam.

É desse pertencimento intelectual do qual fará parte, nos anos subsequentes à sua matrícula na Pontifícia Universitá Gregoriana em Roma, e no qual aprofundará suas crenças, entre elas, as que apontavam para a afirmação da escola católica frente à protestante:

Naqueles dias, me sentia soldado em nova cruzada. Nossos inimigos estavam à frente, como mouros e hereges a falar do tedesco de Wintenberg, que iríamos combater nos colégios católicos de nossa terra. Não nos furtávamos à guerra. Bastava nos municiar nas bibliotecas do Pio Americano (PEDROSA, 1927, p. 34, grifos nossos).

Destarte, aqueles dispositivos, fossem políticos, sociais ou instrucionais, precisavam ser combatidos, segundo o que esperava a intelectualidade católica, tanto a partir das referidas encíclicas quanto dos discursos combativos expostos. Aspecto a potencializar uma nova geração de estudantes católicos com o pé fincado em questões mal resolvidas, ainda no Império. Odilon Pedrosa era um deles.

Nesse sentido, procurou, desde fevereiro de 1927, data de chegada à Itália, adquirir um acervo inicial daquele que seria o núcleo de sua pequena, mas seletiva biblioteca particular, anos depois, um organizado acervo, em sua residência na Paraíba. Todo um cabedal de leituras teológicas, alinhadas com o ultramontanismo, bem como o acesso à literatura em língua italiana, francesa e também portuguesa, reforçaria uma erudição que ele buscou de forma efetiva adquirir. Expressiva marca daquela segunda fase em sua formação intelectual, e também momento de experiência cosmopolita, diferente da que, até então, havia experimentado como seminarista nos espaços estudantis de Olinda e Recife. Haja vista que Roma e a Europa entravam em ebulição, no cômputo de uma guerra declarada entre o mundo profano e o mundo sagrado, entre o cientificismo e as confessionalidades.

Era de se esperar o "alistamento de jovens católicos" na frente de batalha, vindos dos mais diversos espaços católicos, dos quais muitos sul-americanos, entre eles, o jovem Odilon Pedrosa, rapidamente, a se animar com as descobertas teóricas feitas no Velho Mundo, algumas já conhecidas no seminário de Olinda, outras acrescentadas pelo clima ainda mais combativo dos corredores do Vaticano, donde uma espécie de ressaca frente aos avanços laico/seculares por todo o mundo, desde o Oitocentos, fazia-se marcante. 
Não era sem importância o destaque dado pelo Bolletino Degli Studanti (1927, p. 312) ${ }^{5}$, publicação produzida pelo Colégio Pio Latino-Americano, à presença de alunos, recentemente chegados da América.

A fileira dos nossos está engrossada pelo valioso contingente de novos moços que deixaram a patria e vieram se aquecer na fé e nos calores de Pedro, no Colégio Americano. Nós todos exultamos de alegria. Os novos são P.P. de Affonseca e Nery, os srs Pedrosa, Carlos Barreto, Mayer, Moacyr, Salim, Scherer, Dutra, Mascarello, João Reitz e Sebastião Vianna. Incendidos de um mesmo ideal, todos nos empenharemos com esforço na acquisição das virtudes e da sciencia , devidas ao ministro de J.Christo (BOLLETINO DEGLI STUDANTI, 1927, p. 3, grifos nossos).

Inicialmente, esses mesmos seminaristas se integrariam a uma rotina de leituras nos corredores e bibliotecas do Colégio, onde teriam contato com as encíclicas papais in loco, livros apologéticos, panfletos, manifestos e cartas pastorais. Uma parte delas, a postular os modelos de instrução católica, segundo aqueles documentos, necessários no combate ou no trato das chamadas doutrinas contrárias à fé. Segundo Odilon Pedrosa (1927, p. 23):

Desde os primeiros dias de estudo, nossos mestres destacam a necessidade de ler e estudar, para levar a boa nova contra a instrução errônea, na qual nosso povo mergulha. É ímpar a dignidade e sapiência deles, ao nos mostrarem as táticas dos inimigos da fé na corrupção da escola, da família e da sociedade (PEDROSA, 1927, p. 24, grifos nossos).

Estas últimas, também reproduzidas nas salas de aula, ou recitadas como verdadeiros mantras da militância católica, que se armaria teologicamente, e converteria os espaços dos seminaristas, de dormitórios a salas de oração, em seguidas praças-forte. Como destaca Odilon Pedrosa (1927, p. 35): "Frente aos hereges tínhamos a escola católica como modelo a seguir". O seminarista Pedrosa, como seria conhecido no Colégio, mergulhou desde muito cedo numa série de leituras doutrinárias, que se somavam às que já havia feito no Seminário de Olinda.

Leituras, que passavam por autores inicialmente italianos. Entre os livros encontrados, anos depois, em sua biblioteca no Brasil, trazidos entre seus pertences, encontravam-se: La nostra predicazione: pensieri e consigli, de Paulo Guglielmo Von Keppler, e séries apologéticas, tais como as que eram publicadas nos ambientes estudantis romanos, e a circular por décadas, constando entre suas obras Il católico premunido congro vli attacchi dei protestante, de Francesco Ouglati. Esta última obra, de profundo impacto em seu acervo particular de escritos, e leituras contra a educação protestante.

Também é do período uma grande série de boletins impressos que circulavam no Colégio Pio Latino-Americano e que, embora fossem de matriz italiana, no tocante à editoração e localidade da impressão, incluíam a publicação de textos em português, destinados a alunos brasileiros na instituição. Na série do Bolettino Degli Studanti, mantida por Odilon Pedrosa, constam estudos apologéticos, traduções, artigos, cartas pastorais e crônicas sobre a vida estudantil, escritos em português.

Todas as atividades, diga-se, desenvolvidas ao longo do ano letivo, acabavam sendo publicadas quinzenalmente. É marcante, inclusive, a presença de trabalhos discentes, nos quais eram expostos os debates intelectuais do período. Entre eles, os postulados que atentavam para a instrução católica e sua difusão, nos quais o papel destinado aos futuros padres era publicizado continuamente.

A construção de um repertório intelectual em língua portuguesa, especialmente fundamentado de forma a aglutinar práticas e instrumentais para expansão do modelo 
instrucional católico se apresentava rotineira, livremente, à disposição dos estudantes brasileiros, assim como de outras nacionalidades.

Na memória de Odilon Pedrosa (1950, p. 23): "Naqueles tempos, ensaiávamos as primeiras letras no combate católico. Expúnhamos nossa visão do mundo. Aceitei a missão de representar nossos compatriotas brasileiros no Colégio e no Bolettino como uma dádiva”.

Destarte, na forma de organização do principal impresso do Colégio Pio LatinoAmericano, o Bolettino Degli Estudanti, depositado nas salas de estudo e biblioteca do Colégio Pio Latino-Americano, e da Pontifícia Universitá Gregoriana, constituíam-se importantes os editoriais bilingues, dispostos a partir da configuração cultural/linguística castelhana, italiana e portuguesa.

Números do Bolettino, de forma sistemática, alternavam a publicação de artigos, crônicas, foto-reportagens, encíclicas e uma série de enxertos de textos oficiais da Igreja, todos publicados ao longo das seções em que se divulgavam artigos de estudantes latinos. Condição, digamos, estratégica para os que se prestavam a retornar à América do Sul nos meses seguintes, a incluir em seus pertences uma série de prédicas quanto ao trato com certa moral cristã, considerada adversária, nos quais o protestantismo era um dos alvos preferenciais. Bem como, também se apresentaria como medida profilática a prática de um jornalismo engajado, a ser desenvolvido pelos futuros padres ordenados.

Um extenso cabedal de simbologias, evidentemente, tomaria de assalto o repertório intelectual que haveria de marcar aquela passagem na Europa. Em suas memórias, Odilon Pedrosa (1950, p. 14) destacaria: "mesmo depois de desembarcado no Brasil, dois anos depois de minha ordenação, continuaria a receber as notícias que chegavam do Colégio em Roma".

Naquele universo, que postulava a ação social da Igreja, nos mais diversos nichos intelectuais, tocou fundo nas práticas que se manifestaram cada vez mais valorizadas por Odilon Pedrosa: a intransigência em relação aos dísticos da instrução não católica, onde importava a guerra sem quartel aos postulados da instrução não católica, fosse ela de qualquer matriz.

$\mathrm{Na}$ Europa, deu especial atenção às discussões contidas no Bolettino Degli Studanti, cujos debates eram atrelados à ação social católica; à crítica das práticas escolares; e, especialmente, às sínteses de debates apologéticos, que se processavam em outros idiomas e que acabavam publicados em português, naquele suporte impresso.

Uma parte significativa das cartas encíclicas, cartas pastorais e manifestos produzidos na Itália, fosse no ano de 1927, ou produzidos nos anos anteriores, que eram lidos com afinco na chamada comunidade brasileira, também acabaram enviados ao Brasil, a partir de sua correspondência com a revista Maria, publicação atrelada à congregação mariana secção de Pernambuco, e importante órgão de divulgação dos debates, eventos e encíclicas papais no Brasil.

Junto àquela publicação, Odilon Pedrosa exercitaria sua prática jornalística, função na qual faria escola, e se aprimoraria no trato com o "ofício militante", extremamente útil, nos anos posteriores, como destaca Odilon Pedrosa (1950, p. 35), na identificação do ambiente de estudo e trabalho romano:

"Estávamos excitados com as palestras, as visitas pastorais e o mundo de textos que sempre estava à vista. Todos os dias líamos jornais de toda parte da Europa. Do observatore ao Ilustração 
católica (...). O clima era otimista e as armas estavam a ser reforçadas. Escrevia no Bolettino Degli Studanti e na Revista Maria (PEDROSA, 1950, p. 34).

Todo um cabedal de referências se afirmaria nos meses e anos seguintes, na participação de Odilon Pedrosa junto a um círculo combativo e de militância católica, junto aos preceitos de recristianização da sociedade. Uma viagem a Portugal: nascedouro de uma biblioteca militante.

\section{A circulação da militância e do modelo cultural católico}

A segunda metade do ano de 1927 foi uma etapa de suma importância na vivência de Odilon Alves Pedrosa, como estudante e como intelectual, principalmente devido à sua experiência pessoal na passagem por França e Portugal. Movidos por um ideal de peregrinação, que incluía visitas a santuários e espaços de convívio e de produção intelectual, o seminarista pernambucano e mais cinco estudantes do Colégio Pio LatinoAmericano se deslocaram para Lourdes, na França, a partir de Roma.

Como diria Odilon Pedrosa, em seu Diário de estudante em Roma (1927, p. 7), que foi parcialmente publicado em crônica de viagem, no Bolettino Degli Studanti ${ }^{6}$ : "Navegamos de Óstia a Narbonne e dalí para Lourdes de carro. Uma viagem difícil mas que renovou nossas preces. Estávamos na presença de Maria e de seus defensores" . Após a peregrinação ao santuário, a segunda etapa da viagem missionária se deslocou pela Espanha em direção a São Tiago de Compostela, embora tenham estado, devido a complicações e enfermidades entre os seminaristas, em Braga e no Porto, ao norte de Portugal. Um desvio no roteiro original, que teria consequências diretas na construção da biblioteca de Odilon Pedrosa, mas também no cabedal de referências teóricas, a se somarem às do mundo latino e francófono, como declararia, à guisa de justificativa, Odilon Pedrosa (1950, p. 9):

(...) Não pudemos ir a Santiago, devido a enfermidades entre os nossos. Assim, era de suma importância contatar religiosos em Portugal ainda recentemente proclamada a República, para entendermos a experiência de luta pela instrução católica em um sistema hostil a instituições confessionais. Era sabido os sofrimentos dos párocos portugueses em tempos de laicismo Deus nos levou a Portugal (PEDROSA, 1950, p. 9).

Quando da visita pastoral, por via terrestre, a Braga e depois Porto, viria a se afirmar, por parte de Odilon Pedrosa, o acesso a todo um repertório de leituras, a serem adquiridas nas livrarias da cidade, e na qual se apresentavam debates de profunda influência na formação do seminarista. A existência de obras como Crítica a Crítica, do padre português José Joaquim de Senna Freitas, em sua biblioteca, praticamente intacta, deve-se a esses primeiros dias em Portugal.

Visita breve, ao longo de 15 dias, mas que tomaria um sentido ainda mais afirmativo junto ao sentido de catolicidade daqueles visitantes/seminaristas brasileiros. Todos eles ávidos pelo combate, dispostos a entrar em debate com estudantes partícipes de ideários do tempo e nos quais "palavras se tornavam espadas", nos escritos de Odilon Pedrosa (1927, p. 60). Segundo suas memórias, escritas ainda sob o calor dos embates teóricos, entre os defensores da educação laica ou confessional, no Brasil, anos depois da viagem a Portugal:

O cansaço da viagem que dirigíamos para Braga no Minho, foi esquecida quando de nosso mergulho nas livrarias da Almada no Porto, lugar em que adquirimos livros do grande líder 
cruzadista moderno. O Senna Freitas. Alí comprei meu primeiro livro deste grande herói que levaria comigo, assim como tantos outros (PEDROSA, 1950, p. 38-39).

Em sua trajetória intelectual, na construção de uma série de postulados que reproduziria ao longo de sua carreira, estava a percepção muito efetiva dos modelos instrucionais adversários da escola católica, absorvendo em seu metié intelectual os postulados contra a instrução protestante, temática recorrente junto à literatura militante portuguesa. Base religiosa que o seminarista, depois padre, jornalista e diretor de ginásio, considerava uma das maiores ameaças ao modelo de escola católica. Assim leu, de forma ávida, a partir de Senna Freitas, sobre as polêmicas que assolavam Portugal e o Porto e bebeu argumentos apologéticos, em três semanas de estadia em Portugal. Em suas memórias, inclusive, faz inúmeras referências ao intelectual lusitano:

(...) o grande padre dos Açores nos alerta sobre o grande mal de Winteberg. Nos conforta ao apontar o verdadeiro modelo de sociedade e que, penso, deve nortear a instrução. A ele devemos o tacape a brandir sobre a cabeça dos hereges em terras pernambucanas. Sejamos seus discípulos. Honremos a escola catholica, combatamos os preceitos heréticos (PEDROSA, 1950, p. 7).

A observar a quantidade de obras (43 livros) daquele intelectual, constantes em sua biblioteca, podemos mensurar a compreensão e crítica da questão da instrução protestante que se fixou em seu repertório combativo, de crivo marcadamente romanizado. Em um dos livros de sua biblioteca se encontraria grifada, por exemplo, uma passagem marcante do olhar de Senna Freitas para a doutrina:

Felizmente os protestantes são sempre melhores que o seu protestantismo, aliás, se fossem coerentes, deixavam a perder de vista as abominações da antiga Roma verberadas pelo chicote de Juvenal (...) mas esses taes são os protestantes de boa fé, os heresiachas que crearam a reforma foram os que mais largamente tiraram as consequências do principio da não necessidade das boas obras (FREITAS, 1884, p. 34).

Aquela primavera de 1927 se manifestaria profícua no aprofundamento e no fomento das posturas missionárias ultramontanas, que Odilon Pedrosa recebia como instrução para seu retorno ao Colégio Pio Latino-Americano e à Pontifícia Universitá Católica. Especialmente, num Portugal onde o avanço do ideário protestante de instrução se apresentava em expansão nos espaços urbanos, como destaca Afonso, (2009, p. 45). Não sem antes estar a percorrer alfarrábios, os corredores da arquidiocese de Braga e a visitar colégios naquela cidade. Este último aspecto, devemos destacar, a causar profunda impressão na memória do seminarista, e na idealização por parte do Odilon Pedrosa de espaços instrucionais católicos. Odilon Pedrosa (1927, p. 56) infere ainda: "Há de acharmos espaço em Pernambuco para fundarmos escolas tais como aqui em Braga. Quando aprofundaremos nossa cruzada, sem quartel contra a mundanidade".

Impressão que usaria no combate ao protestantismo e sua prática instrucional, ao liderar gerações de jovens estudantes na Paraíba do Norte, onde se fixou como educador. Rotineiramente se manifestaria ao relembrar as escolas católicas de Portugal e Senna Freitas, do qual colecionaria livros comprados na viagem, como verdadeiros troféus.

Da mesma forma, a estadia no Porto, onde a comitiva de seminaristas brasileiros se instalara numa pensão, também serviu de base para incursões pelas praças, confeitarias e livrarias da cidade. Lugares donde se manifestavam acalorados debates, e nos quais Odilon Pedrosa adquiriu um importante acervo de livros, panfletos e revistas que manteve consigo, mesmo passados anos da visita, tais como a Pastoral Coletiva do Episcopado português, documento assinado, por Dom Manuel Vieira de Matos e acessado pelos seminaristas do Pio Americano ao receberem cópias da União (Revista católica lisboeta), diretamente das 
mãos daquele líder, quando da despedida de Braga para o Porto, e de lá para a Itália, segundo seu relato, lida com afinco como modelo documental semelhante à proposta pelos bispos no Brasil em 1915. Somar-se-ia àquela pastoral uma série de obras que Odilon Pedrosa colecionou na sua biblioteca, e que o mesmo, sempre que tinha oportunidade, referenciava em suas memórias.

Entre elas estavam: A Nova Geração, de Diogo Pacheco D'Amorim; do padre Senna Freitas: No plesbítero e no templo, Dia à dia de um espírito christão, e Os Nossos bispos do continente; O Christianismo e o progresso, de António da Costa; O Catholico no século de João Bosco; Regras da Igreja na formação do clero, de autoria de António Ferreira Pinto $^{7}$. Obras que representam apenas uma parte do acervo em língua portuguesa a servir de fundamento intelectual para suas atividades discentes, durante sua estadia na Itália como seminarista e, anos depois, já no Brasil, como pároco e diretor do Colégio Diocesano Pio XI de Campina Grande.

De qualquer forma, chegaria ao porto de Recife no final de 1927. Especialmente motivado e ordenado padre, com título de doutor em Direito Canônico pela Pia Universitá Católica de Roma, assumiu, de imediato, funções administrativas na Arquidiocese de Nazaré da Mata, onde exerceria cargo de reitor do Seminário Maior e diretor da redação da Gazeta, de Nazaré, lugar em que executaria os projetos fomentados na Europa e projetados ainda como estudante no Seminário de Olinda.

\section{Considerações Finais}

A circulação dos discursos de romanização e recristianização da sociedade, a partir do missionarismo, também foi marca pontual na militância católica. Ainda permanecem lacunar os estudos que apontem as ramificações no universo católico de língua portuguesa, especialmente, no papel exercido pelos seminaristas em congraçamento com a Sé Romana, a se manifestar como estratégia factível de expansão católica, nas primeiras décadas do século XX.

A doutrinação e projeção de práticas escolares sancionadas por discursos católicos, que alertavam sobre os perigos atrelados às doutrinas denominadas heréticas, entre elas a maçonaria, e religiões cristãs não alinhadas com Roma, como as protestantes, lançaram-se como projetos afirmativos da catolicidade.

É marcante perceber que boa parte das especificidades e estratégias combativas, escritas em português, acabasse tendo uma importância efetiva na trajetória de formação de seminaristas brasileiros em visita à Europa, haja vista terem aqueles estudantes retornado ao Brasil sob forte impacto das ideias que circulavam no universo católico de língua portuguesa, e nas quais a instrução protestante era alvo a ser combatido. Não só pelas mãos da literatura, escrita em francês ou italiano, idiomas em que se apresentavam obras clássicas da apologética cristã, mas dentro de quadros intelectuais e militantes lusobrasileiros. Particularmente, na redistribuição e adaptação dos preceitos para a escola cristã, fundamentados pelos textos lidos e adicionados aos acervos dos padres em retorno ao Brasil, de suas missões na Europa, tais como Odilon Alves Pedrosa, em Pernambuco e na Paraíba. 


\section{Referências}

AFONSO, J. A. M. M. Protestantismo e Educação: história de um projeto pedagógico alternativo em Portugal na transição do séc. XIX. Braga: Universidade do Minho, 2009. p. 65 .

AZZI, R. História da Igreja no Brasil: Terceira Época: 1930-1964. Rio de Janeiro: Vozes, 2008. p. 11-50.

BOlletino DeGli Studanti, Colégio Pio Latino Americano, Roma, v. 1, n. 4, p. 3, 1927.

BOURDIEU, Pierre. A economia das trocas simbólicas. Tradução de Sergio Miceli, Silvia de Almeida Prado, Sonia Miceli e Wilson Campos Vieira. São Paulo: Perspectiva, 1987.

CAMBI, F. História da Pedagogia. São Paulo: EDUSP, 2002. p. 340-370.

CATROGA, Fernando. Entre Deuses e Cesares. Lisboa: Almeidina, 2010.

CHARTIER, Roger. A história cultural: entre práticas e representações. Lisboa: Difel, 1990.

FREITAS, José Joaquim de Senna. No plesbítero e no templo. Lisboa: Lallemand, Fréres, 1884. v. I.

JULIA. Dominique. A cultura escolar como objeto histórico. Revista Brasileira de História da Educação. Campinas: Autores Associados, 2001.

KEPPLER, Paulo Guglielmo Von.La nostra predicazione: pensieri e consigli. Roma, 1927.

MARRAMAO, Giacomo. Poder e Secularização. As categorias do Tempo. São Paulo: UNESP, 1994. p. 15-57.

MARTINA,Giacomo. História da Igreja, De Lutero aos nossos dias, v. III, A Era do Liberalismo. Tradução: Orlando Soares Moreira. São Paulo: Loyola, 1996.

MEZZOTI, Daniele. A Igreja Católica e a Secularização. São Paulo: Paulinas, 1998. p. 49-60.

MICELI, Sérgio. A Elite Eclesiástica brasileira, 1890-1930. Rio de janeiro: Bertrand, 1988.

NEVES, Margarida de Souza. Os cenários da República. O Brasil na virada do século XIX. In: DELGADO, Lucilia de Almeida Neves; FERREIRA, Jorge (Org.). O tempo do liberalismo excludente. Da proclamação da República à Revolução de 30. Rio de Janeiro: Civilização Brasileira, 2003. p. 19-56.

OZOUF, M. La fête révolutionnaire: 1789-1799. Paris: Gallimard, 1976.

PASTORAL COLETIVA DO EPISCOPADO PORTUGUÊS. Lisboa: A União, 1927.

PASTORAL Coletiva dos Senhores Arcebispos e Bispos das Províncias Eclesiásticas de S. Sebastião do Rio Janeiro, Mariana, Cuiabá e Porto Alegre. Rio de Janeiro: Typographia Leuzinger, 1915.

PEDROSA Odilon Alves. Diário de Estudante em Roma. Manuscrito. Roma, 1927. 
Memórias do seminário. Manuscrito. Sapé, Paraíba, 1950.

PINTASSILGO, Joaquim (Org.). Laicidade, Religiões e Educação na Europa do Sul no século XX. Instituto de Educação: Universidade de Lisboa, 2013.

SILVA, Ramsés Nunes e, Signal dos Tempos: modernidade, secularização e laicização na instrução pública da Parahyba do Norte (1867-1902). João Pessoa:UFPB, 2006.

VILlAÇA, Antônio Carlos. O Pensamento Católico no Brasil. Rio de Janeiro: Civilização Brasileira, 2006.

ZAGHENI, Guido. Curso de História da Igreja. A Idade Contemporânea. São Paulo: Paulus, 1999. p. 43-69.

\section{Notas}

${ }^{1} \mathrm{O}$ referido artigo está relacionado ao relatório e projeto de pós-doutoramento: Impressões sobre a instrução protestante no universo de língua portuguesa constantes na biblioteca do padre Odilon Alves Pedrosa (1888-1932). Encaminhado junto ao repositório da Universidade do Minho. Consta, naquele espaço, a formatação inicial do referido trabalho.

${ }^{2}$ Professor doutor, vinculado ao departamento de Arquivologia da Universidade Estadual da Paraíba.

${ }^{3}$ Professor doutor, vinculado ao Instituto de Educação e ao Centro de Investigação em Educação (CIEd) da Universidade do Minho (Portugal).

${ }^{4}$ PEDROSA, Odilon Alves, Diário de Estudante em Roma. Manuscrito. Roma, 1927.

${ }^{5}$ O Bolletino Degli Studanti foi uma publicação interna dos discentes do Pio Colégio Latino-Americano, na cidade de Roma, a circular com alguma regularidade. Odilon Pedrosa, em sua estadia na cidade, foi articulista de inúmeros textos e prédicas publicadas junto à comitiva brasileira do Colégio.

${ }^{6}$ BOLetTino DeGli STUdANTI. Missão Católica em Portugal. Impresso. Roma, 1927.

${ }^{7}$ Todas elas, obras que se encontram no acervo do Padre Odilon Alves Pedrosa. Acervo, atualmente em processo de estruturação, diagnóstico e digitalização, como parte de nossa atividade de pesquisa atrelada ao CNPQ.

Recebido: $\quad$ março-16 Aprovado: setembro-16 